\title{
Disturbed Chylomicron Metabolism in Type 2 Diabetes - A Preventable Cause of Atherosclerosis?
}

\author{
Gerald H. Tomkin and Daphne Owens \\ Diabetes Institute of Ireland, Beacon, and Trinity College Dublin
}

Ireland

\section{Introduction}

Diabetes remains a fascinating condition to observe and treat, at least for the authors. The rewards of observing patients who remain free of complications many, many years after diagnosis is however negated by seeing the terrible consequences of diabetic complications which occur, not only in patients who have had the disease for many years but also in those who are found to have the disease when they first present with complications. The evolution of diabetes care has been fueled by new pharmaceutical agents and the large trials that have followed demonstrating benefit. There have of course been occasional trials that have upset patients, diabetologists and people looking after diabetes as well as the pharmaceutical industry. An example early in my career as a diabetologist was the University Group diabetes program (UGDP) [1] which suggested harm rather than benefit from the sulphonylurea Tolbutamide and the biguanide Phenformin. The controversy which this trial caused was truly amazing involving the Supreme Court in the United States. Not many trials have been scrutinized by a national supreme court. A more recent example is the ACCORD study [2] which set out to examine the benefit of reducing blood sugar to below $6 \mathrm{mmol} / \mathrm{l}$. This study was stopped early because, although there was a reduction in myocardial infarction there was an increase in mortality. These trials have resulted in a magnificent increase in speculative literature and new consensus statements from lots of different bodies enthusiastic about giving advice through guidelines. The Annals of Internal Medicine is to be congratulated on publishing a paper written by Davidof "Music lessons; what Musicians can teach Doctors"[3]. The care of diabetes is certainly both an art and a science in 2011 and this article should re-enforce the diabetologist to be secure in practicing art as well as science in the management of diabetes.

Cardiovascular disease is unfortunately the major cause of death in patients with diabetes. For example in the San Antonia Heart Study Halfner et al [4] demonstrated the increased risk of cardiovascular mortality in patients with diabetes but without a previous MI was the same as that of non diabetic patients who already have had MI although another study disputed this [5]. A third prospective study in Finland demonstrated similar results to the San Antonia Study [6] and a metanalysis in 2009 confirmed this relationship [7]. Looking at the situation in a different way it has been shown that diabetic patients have a life expectancy 8-15 years less than non-diabetic people. Recently a prospective study of men aged 60 - 69 years followed up for 9 years was reported [8]. The authors found that only 
men with early onset diabetes and a duration of 16.7 years showed cardiovascular risk similar to those with MI and no diabetes. Late onset diabetes was also associated with increase in coronary artery events and all cause mortality compared to non diabetic men who had no coronary heart disease (CHD), but the risk was less. Even more worryingly is the evidence that as blood sugar rises but is still within the pre-diabetes range the risk of cardiovascular disease increases [9-11]. Indeed the risk increase in percentage terms is greater in this group of patients than in those with diabetes.

Insulin resistance is a very early finding in the progression to diabetes and it has been suggested that abnormalities in fatty acid oxidation can be seen in close relatives of diabetic patients at an early age in adulthood [12,13] . A recent report from the Framingham Heart study has examined the effect of insulin resistance in subjects without diabetes. During a follow-up mean of 14 years the incidence of CHD was significantly greater in those with insulin resistance confirming previous studies that demonstrated that high insulin levels without hyperglycaemia was an important risk factor[14]. Hba1c has been shown to predict cardiovascular events and cardiovascular mortality independently of known cardiovascular disease [15-16]. These studies show a consistent and continuous relationship between glycaemia and cardiovascular risk even below diagnostic levels for diabetes. Chanman et al [17] have recently looked at non diabetic hyperglycaemia and cardiovascular risk and have demonstrated that in people with non-diabetic hyperglycaemia cardiovascular risk is highly dependent on the presence of other cardiovascular risk factors such as dyslipidaemia. These results are in keeping with the difficulty in demonstrating that lowering blood sugar improves cardiovascular outcome. There are of course some studies that show this ie Diabetes Control and complications/ Epidemiology of Diabetes Interventions and Complications (DCCT/EDIC) and UK Prospective Diabetes Study (UKPDS) follow-up [18.19]. However the original UKPDS did not show a significant effect on cardiovascular mortality [20]. A recent report from the FRENA registry [21] has shown in secondary prevention that patients with diabetes and $\mathrm{HbA1c}<7 \%$ had a lower incidence of subsequent ischaemia and a lower mortality than those with HbA1c $>7 \%$. These differences appeared only in patients with coronary artery disease (CAD). In this study more than 900 patients with type 2 diabetes were followed up over a mean period of 14 months [2, 21]. In the intensive care unit setting there was great excitement when studies showed that there was benefit from meticulous control of blood sugar but many studies since then have not confirmed these findings with regards to cardiovascular mortality [22,23].

\section{Atherosclerosis in diabetes}

Diabetes has been defined as an absolute or relative lack of insulin and it is therefore reasonable to consider the action of insulin and to recognize that deficiency in insulin does not lead only to hyperglycaemia but also to disturbance in fat and protein metabolism. Atherosclerosis is a condition of cholesterol and fat deposition in a vulnerable endothelium surface of an artery. It is not surprising therefore that attention has shifted, admittedly very slowly from the concept of dysglycaemia to dyslipidaemia for the cause of atherosclerosis in diabetes. Inspiration has come from the work of Shafrir and Guttman [24] who in 1965 demonstrated the relationship between free fatty acids and blood sugar. They divided into quartiles, people ranging from normal blood sugar to impaired glucose tolerance. They demonstrated that non-suppression of free fatty acids occurred as the blood sugars rose even in the normoglycaemic range. In a thought provoking review many years later Shafrir and Raz [25] made the suggestion and gave strong evidence to support the suggestion that Diabetes Mellitus should be renamed "Diabetes Lipidus". 


\section{Atherosclerosis}

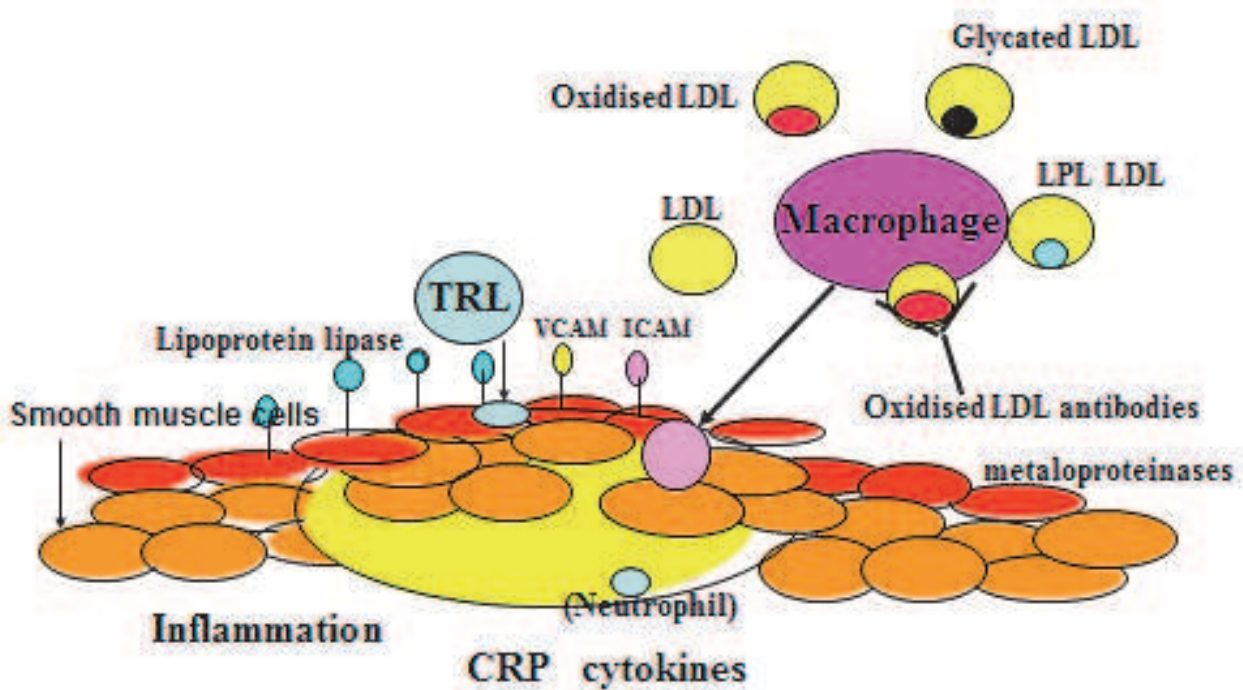

Fig. 1. LDL may become modified by oxidation, and glycation. The macrophage takes up modified LDL and enters the subendothelial space where it becomes a cholesterol laden foam cell. Macrophage uptake is facilitated by cytokines and chemotactic factors such as VCAM and ICAM. Uptake of cholesterol from triglyceride-rich lipoproteins is facilitated by lipoprotein lipase on the endothelial cell surface. Smooth muscle cells protect the plaque from rupture through metalloprotinases and thrombus formation.

Poorly controlled diabetes is usually associated with hypertriglyceridaemia which very often responds to hypoglycaemic therapy and normalization of blood sugars. The nonsuppression of free fatty acids (FFA) results in excess free fatty acids reaching the liver from adipose tissue which in turn leads to an increase in very low density lipoprotein (VLDL) secretion in the postprandial phase. The cellular concentration of non esterified fatty acids (NEFA) is tightly controlled by the balance between triglyceride hydrolysis and NEFA esterification [26-28]. The hydrolysis of the primary and secondary ester bonds between long chain fatty acids and the glycerol backbone in triglyceride is called lypolysis and depends on specific hydrolases commonly designated lipases. Adipose triglyceride lipase (ATGL) selectively performs the first and rate limiting triacylglyceride hydrolysis to form diacylglycerol and NEFA [29, 30]. Hormone sensitive lipase hydrolyses tri-, di- and monoacylglycerol [31]. Monoglyceride lipase efficiently cleaves monoglycerols into glycerol and NEFAs. Thus lipoprotein lipase, together with adipose triglyceride lipase, hormone sensitive lipase and hepatic lipase are all involved in the storage and release of FFA and are all involved in the metabolism of the triglyceride-rich lipoproteins and the suppression of fatty acids within the adipocyte. Insulin has a direct effect in inhibition of hormone sensitive 
lipase and ATGL which releases fatty acids from the adipocyte and stimulates lipoprotein lipase which is involved in the delipidation of the triglyceride-rich lipoproteins necessary for lipoprotein clearance and FFA storage in the adipocyte. For review see Lass et al 2011 [32]. NEFA metabolism strongly effects glucose utilization and insulin resistance. ATGL affects glucose metabolism by different mechanisms and in a tissue specific manor ie measures of insulin signaling are increased in skeletal muscle and white adipose tissue but decreased in brown adipose tissue [33]. In pancreatic islets ATGL deficiency causes triglyceride accumulation and impairs fuel and non fuel stimulated insulin secretion suggesting that ATGL is required for the provision of NEFAs as energy source in the process of insulin secretion.

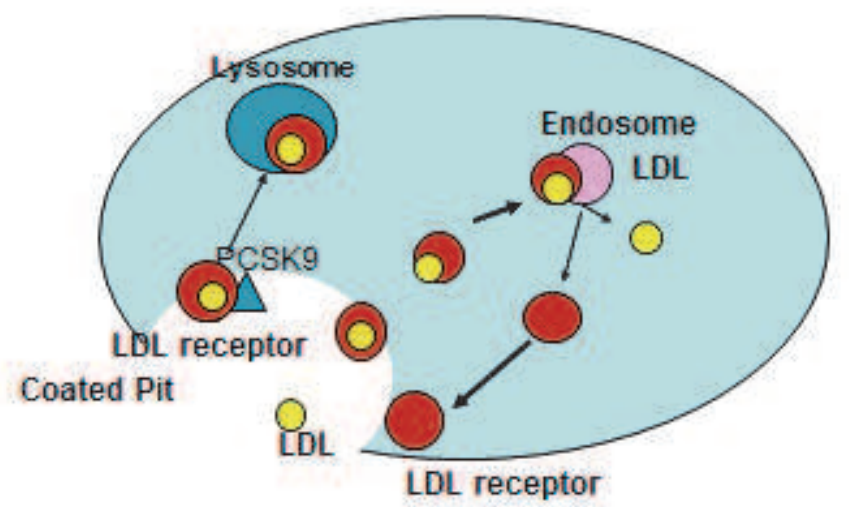

Fig. 2. LDL is cleared from the plasma by uptake by the apo B/E receptor in coated pits on the cell surface. The receptor is internalised and transported to the endosome where LDL is degraded and the cholesterol released. The receptor is normally recycled to the cell surface. PCSK9 is secreted into the pasma and binds to the LDL receptor inhibiting recycling of the receptor. Statins work by upregulating the LDL receptor and facilitating LDL clearance but they also upregulate PCSK9.

Cholesterol as a risk factor for atherosclerosis is so well documented that further confirmation seems unnecessary. The safety and efficacy of lowering cholesterol is also well established [34]. Long term prospective studies such as Framingham laid the foundations but examination of monogenetic hypercholesterolaemia, whether it be from apo B polymorphisms, the low density lipoprotein (LDL) receptor or the recent pro-protein convertase subtilism-like/kexin type 9 (PCSK 9) already had made the association between hypercholesterolaemia and atherosclerosis. PCSK9 is of particular interest since there are both loss of function and gain of function gene polymorphisms. In 2003 Abifidel et al [35] reported 23 families with autosomal dominant hypercholesterolaemia and premature CHD caused by missense mutations of PCSK9. Haughton et al in 2007 [36] demonstrated that over expression of PCSK9 in livers of mice reduced hepatic LDL receptor protein causing hyperchlesterolaemia suggesting that the mis sense mutations caused a gain of function to the mutant protein. They also showed that inactivation of PCSK9 resulted in hypocholesterolaemia. Loss of function mutations have also been identified in patients with 
hypocholesterolaemia. What is particularly interesting is that the reduction in cholesterol with these loss of function mutations is associated with much less coronary artery disease than would be expected with a similar reduction in cholesterol using statins. An explanation has been that the miss-sense mutation has been there since birth whereas statins are only used in middle age [37]. Statin therapy in heterozygous patients with this polymorphism has a much greater effect than would be associated with statins alone and these findings have been used to promote the idea that early statin use would increase benefit [37]. Statins upregulate sterol regulatory element binding protein (SREBP) which upregulates the LDL receptor but also causes a $45 \%$ increase in PCSK9 and a 70\% increase when ezetimibe is added to the statin [38]. This is probably through regulation by SREBP thus development of cholesterol lowering drugs which do not increase PCSK9 would be very advantageous [39]. PCSK9 promotes LDL uptake by the LDL receptor but reduces the number of LDL receptors. Exciting animal studies suggest that inhibitors of PCSK9 may prove to be a powerful tool in cholesterol lowering particularly in conjunction with statins [40]. The Sammomys obesus (sand rat) has been very successfully used as a nutritionally-induced type 2 diabetes model [41]. Levy et al [42] investigated intestinal PCSK9 protein in this model and found that the protein was diminished and LDL receptor was raised in the diabetic compared to non-diabetic Sammomys. To investigate whether PCSK9 expression in diabetic patients played a part in diabetic dyslipidaemia, Brouwers et al [43] in the CODAM study measured PCSK9 in subjects with normal glucose metabolism with impaired glucose metabolism and type 2 diabetes. They found no difference in plasma PCSK9 between the 3 groups. Their study did suggest that the presence of type 2 diabetes may modify the relationship between plasma PCSK9 non-HDL cholesterol and apo B.

Early studies with statins such as the $4 \mathrm{~S}$ study, demonstrated that diabetic patients responded better if anything than non-diabetic patients to statin therapy [44]. Other studies such as the Heart Protection Study [45.46] suggested that the response was similar in diabetic and nondiabetic patients. The role of hypertriglyceridaemia as a risk factor is less secure, perhaps because of the very strong inverse relationship between HDL cholesterol and the strong evidence that HDL protects against MI through various pathway [47]. Four years ago 2 important large studies demonstrated convincing evidence of the association between hypertriglyceridaemia and cardiovascular disease [48, 49]. Both these studies suggested that postprandial triglycerides are effective in predicting cardiovascular risk which fits in well with the concept of the atherogenicity of postprandial lipoproteins as will be discussed later. A recent examination of the diabetic patients in the Dutch and Potsdam contributions to the European Investigation into Cancer and Nutrition[50,51] was reported. The aims of the study were to examine the effects of postprandial time on the association and predictive value of non-fasting lipid levels and cardiovascular disease risk in participants with cardiovascular disease and diabetes. More than 1300 participants with diabetes at baseline were analysed. A cut off time between the groups of 3 hours was used in the assessment of cardiovascular risk prediction. The authors concluded that postprandial time did not influence the association of lipid concentrations with CVD in patients with diabetes nor did it effect a prediction of CVD risk [52]. The dramatic effects of cholesterol reduction with statins in reducing cardiovascular events has not been replicated using drugs such as fibrates which lower triglycerides although studies such as the DIAS study [53] did show significant lack of progression of coronary artery atherosclerosis using fenofibrate and the FIELD study [54] did show a significant reduction in 
the composit of CVD death, MI, stroke and coronary or carotid revascularization, even though many patients in that study had statins added to the treatment during that study and only $21 \%$ of patients enrolled had mixed dyslipidaemia, thus limiting its power. Also the Field Study [54] chose patients who did not have very elevated triglyceride levels which was anther problem with the study. A recent metanalysis systematically searched trials published between 1950 and 2010 and found that fibrates produced a 10\% relative risk reduction for major cardiovascular events and a $13 \%$ relative risk reduction for coronary events $(p<0.001)$ but had no effect on all risk or cardiovascular mortality[55]. Supporting the concept that fibrates may show more benefit in patients with hypertriglyceridaemia, Scott et al [56] on behalf of the Field Study Investigators explored whether the effect of fenofibrate on cardiovascular risk differed in subjects with and without metabolic syndrome. There were more than 9000 individuals with diabetes and components of the metabolic syndrome. They observed that the largest effect of fenofibrate on CVD risk was in patients with marked hypertriglyceridaemia (triglyceride $>2.3$ ) in whom a $27 \%$ risk reduction was observed with or without a low HDL cholesterol. From the above it becomes clear that diabetes is associated with an increased risk of atherosclerosis which can in part be reduced by either lowering LDL cholesterol or triglycerides.

\section{The chylomicron in diabetes}

The food we eat ( quantity and quality) is responsible for the variation in an individuals lipoprotein profile accepting that the variation may be modified by exercise. This regulation is considerably disturbed in diabetes. It is important to recognize the role of the triglyceriderich lipoproteins and in particular the chylomicron in modulating both VLDL and LDL quantity and composition [57]. High density lipoprotein (HDL) is also intimately linked to the triglyceride rich lipoproteins with a strong inverse correlation. Thus the chylomicron assumes dominance over all other lipoproteins particularly in diabetes and makes the study of chylomicron metabolism exciting and of major importance in the pathophysiology of diabetes, dyslipidaemia and atherosclerosis.

The chylomicron is defined by apolipoprotein (apo) B48 its solubilising protein. Many studies have shown an increase in the apo B48-containing lipoproteins both in the postprandial and fasting state in diabetes [58]. Originally it was thought that the problem was in clearance of the particles due to a relative lack of insulin which led to a reduction in lipoprotein lipase activity, slowing of lipolysis of the particle and delayed clearance by the liver. We demonstrated in an animal model of diabetes that chylomicron synthesis was also abnormal and confirmed that because of altered composition of the particle clearance was delayed perhaps due to insufficient apo $\mathrm{E}$ on the particle [59]. The regulation of chylomicron synthesis in the intestine is dependent on the amount of cholesterol that is available in the diet but chylomicron cholesterol also comes from the enterohepatic secretion of bile and the cholesterol that is excreted from the liver via this route as well as de novo cholesterol synthesis. The intestine is responsible for up to $25 \%$ of the cholesterol synthesized in the body. As an interesting aside at this stage it is useful to consider that people have been categorised into high and low absorbers of cholesterol and that cholesterol absorption is inversely related to cholesterol synthesis. As expected the high absorbers do less well on statin therapy but better on inhibition of cholesterol absorption by Ezetimibe, a drug that inhibits cholesterol absorption, compared to the people who are low absorbers of cholesterol. In the Framingham offspring study those patients with lower synthesis and 
higher absorption markers were more likely to develop cardiovascular disease [60,61]. These studies were confirmed by Silbernagel et al [62]. In 2440 participants of the LURIC study they found a modest association of high cholesterol absorption and low cholesterol synthesis with an increased severity of CAD. However Lakoskiet al [63] tested the hypothesis that individuals with high fractional absorption of cholesterol respond better to the cholesterol absorption inhibitor Ezetimibe than to simvastatin and visa versa. They did not find that baseline cholesterol absorption and synthesis predicted responsiveness to the above drugs rather they found that responsiveness to the two drugs was highly correlated. They suggest that factors downstream of the primary sites of action of these drugs are a major determinant of the response. In a subgroup analysis of the Scandinavian Simvastatin Survival Study (4S), Miettinen et al [64] showed that the baseline blood glucose level is related positively to cholesterol synthesis and negatively to that of absorption. Despite a marked glucose-related decrease in cholesterol synthesis with simvastatin, serum cholesterol reduction was not dependent on the baseline glucose level.

The discovery of Niemann Pick C1-like1(NPC1-L1) is an interesting story. The search for an explanation as to how cholesterol in the body is so finely regulated has been intensive. The finely tuned regulation of cholesterol was perhaps best illustrated by the report of the elderly gentleman who ate 25 eggs a day for many years but his cholesterol remained at just above $6 \mathrm{mmol} / 1$ [65]. Altman and Davis in their search for molecules that might inhibit cholesterol absorption discovered by chance a compound which is now known as ezetimibe [66]. They discovered a putative gene, the NPC1L1. Elegant studies in mice demonstrated that knocking out this gene reduced cholesterol absorption by the same amount as happened when the wild mice were fed with ezetimibe. They showed that there was no further reduction in cholesterol absorption in the knockout mice when fed ezetimibe. The group went on to show that lack of Npc1L1 in apoE-/- mice results in a significant reduction in cholesterol absorption and plasma cholesterol levels, and causes nearly complete protection from the development of atherosclerosis, under both cholesterol-fed and non-cholesterol-fed conditions [67, 68]. Statins, which inhibit 3 Hydroxy 3 methylglutaryl co enzyme A (HMGCoA) reductase and cholesterol synthesis, have been shown to increase cholesterol absorption. It has also been shown that low absorbers of cholesterol respond better to statins than high absorbers. Ezetimibe potentiates the effect of statins, increasing their effectiveness by another $15-20 \%$ in relation to cholesterol lowering. Trembly et al [69] this year reported an increase in NPC1L1 by 19\% in the small intestine in subjects on atorvastatin thus describing a mechanism whereby cholesterol absorption is increased in patients on statins. In animal studies we have demonstrated an increase in cholesterol absorption in diabetes [70] We asked the question as to whether diabetes might be associated with an increase in cholesterol absorption through stimulation of NPC1-L1. We demonstrated in animal models of diabetes that NPC1L1 was up-regulated [71] and in diabetic patients and we demonstrated an increase in mRNA [72] suggesting a mechanism for an increase in cholesterol absorption. In the Sammomas Obesus model of type 2 diabetes, the animals exhibiting weight gain, hyperinsulinaemia and hypercholesterolaemia, NPC1-L1 protein and gene expression were both significantly reduced in the intestine and the authors found a lower capacity to absorb cholesterol compared to controls [73,]. This may suggest interspecies variation but it is a surprising finding considering that this animal model of diabetes has been shown to have increased production of intestinal lipoprotein-containing apo B48 [74].

The mechanism whereby the body is almost completely unable to absorb plant sterols was a mystery until recently. Study of the familial condition, sitosterolaemia, unlocked the 
mystery [75]. Sitosterolaemia is a rare condition associated with early and severe atherosclerosis. The condition is associated with normal or slightly elevated cholesterol whereas total sterols are markedly increased. Search for polymorphisms in putative genes controlling plant sterol absorption or perhaps one should say blocking plant sterol absorption, identified ATP binding cassette proteins (ABC)G5 and G8 in the intestine [76]. Further work demonstrated that these two gene products work in tandem to re-excrete both plant sterols virtually completely and cholesterol to a lesser extent in a regulated way [77]. The genes were also found to be expressed in the liver where they are responsible for controlling cholesterol re-excretion into the bile [75-77]. It appears that these two genes are very important regulators of cholesterol and together with NPC1-L1 protein are responsible for cholesterol homeostasasis in the body. Polymorphisms of the ABCG5/G8 have not only been associated with increased serum sitosterol but also with increase in cholesterol. It has also been shown that polymorphisms in the ABCG5/G8 may influence cholesterol in weight reduction programs (the Q604E SNP in ABCG5 and the C54Y in ABC8) [78,79]. Gylling et al [80] examined polymorphisms in the ABCG5 and G8 genes and found that low serum cholesterol and cholesterol absorption were linked to a polymorphism (D19H) of the ABCG8 gene and characteristics of the insulin resistance syndrome in men was linked to Q604E polymorphism in the ABCG5 gene. The authors studied 263 mildly hypercholesterolaemic non-coronary subjects using colestanol to cholesterol ratio as a surrogate marker of cholesterol absorption efficiency. Since diabetes is so frequently associated with dyslipidaemia the ABCs became a target for research. Blocks et al [81] examined mRNA and protein expression of ABCG5 and G8 in the intestine of streptozotosin rats and found significant reduction in expression of both ABCG5 and G8. They found that levels were partially normalised on insulin supplementation. We have shown that ABCG5 and G8 were reduced by more than $50 \%$ in the intestine of zucker diabetic fa/fa rats compared with lean rats although this did not reach statistical significance [82]. Insulin treatment caused a nonsignificant increase in ABCG5 and G8 mRNA. In streptozotosin diabetic rats ABCG5 and G8 were both very significantly reduced in the intestine [83]. There was a negative correlation between both ABCG5 and G8 and chylomicron cholesterol [83]. In the Psamonas Obesus Levy et al [73,74] showed a reduction in ABC G5/G8 in the intestine. In the intestine of human subjects with type 2 diabetes, ABCG5 and G8 mRNA were both significantly lower compared to controls [71]. There was a negative correlation between ABCG5 and G8 and NCP1-L1 in the combined diabetic and control subjects [71]. There was a significant negative correlation between chylomicron cholesterol and both ABCG5 and G8 [71]. These two genes appear to play an important role in the dysregulation of cholesterol metabolism in diabetes

\section{Microsomal triglyceride transfer protein}

Intestinal microsomal triglyceride transfer protein (MTP) plays a major role in the assembly of the chylomicron particle and therefore of cholesterol and triglyceride metabolism. Intestinal MTP has become a hot topic since new inhibitors of intestinal MTP have been shown to lower triglyceride without causing hepatic steatosis at least in animal studies $[84,85]$. Although many polymorphisms of MTP have been described, some of which have considerable impact on LDL cholesterol in both non-diabetic and diabetic subjects [86,87], it is difficult to know whether the results mainly stemmed from the effect in the liver rather 
than the intestine. The intestinal inhibitors of MTP which have no effect on the liver, should answer this question in the future. In animal studies diabetes is associated with an increase in MTP mRNA with close correlation between MTP mRNA and chylomicron cholesterol[81,88-90]. In the rabbit increased MTP mRNA is associated with increase in chylomicron particle numbers [88] but in the rat it is associated with larger particles [89]. The fructose-fed insulin resistant hamster model, has an increase in MTP protein mass and this was associated with an increase in the triglyceride-rich intestinally derived lipoproteins [91]. Zolotowska et al [92] in 2003 examined the B48 containing lipoprotein assembly in the small intestine of psamnonys obesus, a model of nutritionally-induced diabetes and insulin resistance. De novo triglyceride synthesis, apo B48 biogenesis and triglyceride-rich lipoprotein assembly were all increased. MTP activity and protein expression however, were not altered. In the enterocyte of fructose fed golden hamster MTP mRNA and protein mass were increased by tumour necrosis factor(TNF)a but apo B levels in the enterocyte were not effected suggesting that there is considerable inter species variation [91]. In human studies in type 2 diabetes we demonstrated an increase in MTP mRNA in intestinal biopsies $[71,90]$. Diabetic patients who were on statin therapy had lower MTP mRNA compared to those not on statins [86,]. We found positive correlations between MTP mRNA and chylomicron fraction cholesterol and apo B48 [86]

\section{Chylomicron and atherosclerosis}

The circulating chylomicron has been the poor relation of the lipoproteins, at least until recently. There are many reasons for this ie post postprandial lipoprotein measurement is difficult to standardise. The amount of cholesterol that the chylomicron contains is very much less than that of the LDL particle and the statins have demonstrated such resounding success in reducing cholesterol and lowering cardiovascular risk. Those of us who champion the chylomicron as the most important lipoprotein do so in part because the number of chylomicrons, far exceeds that of LDL particles. Chylomicrons in fact carry as much cholesterol as LDL particularly in high cholesterol absorbers. They have a turnover in minutes whereas LDL has a half life of about 4 days. The lipoproteins are a transport mechanism for cholesterol and fat thus the shorter the half life the more the carrying power. The atherogenicity of the chylomicron particle depends on its ability to deliver cholesterol to the atherosclerotic plaque and studies both in animals and humans have demonstrated that indeed apo B48 is found in plaque demonstrating that the chylomicron can enter the endothelial space. The macrophage has a specific apo E receptor which enhances the uptake of the chylomicron particle. The composition of the chylomicron particle in diabetes has been difficult to define because separation of apo B48 particles from apo B100 particles is cumbersome. Using a monoclonal antibody against apo B48, Yoshimura et al [92] examined type 2 diabetic patients and non-diabetic patients. Although the separation of apo B48 from B100 was not complete the apo B48 containing chylomicrons had a higher content of triglyceride but there was no difference between those with diabetes and those without diabetes. They further confirmed a B48 receptor in TPH-1 cells (a human acute monocytic leukaemia cell line) and also in Hep G2 cells. The inflammatory process is at the centre of the atherosclerotic lesion. Chylomicron remnants induce macrophage foam cell formation $[93,94]$. The fatty acid composition of chylomicron remnants markedly influences the formation of macrophage foam cells. The group from the Royal Veterinary College in London has shown that enrichment with saturated fatty acids causes the remnants to be 


\section{Cholesterol absorption and chylomicron synthesis}

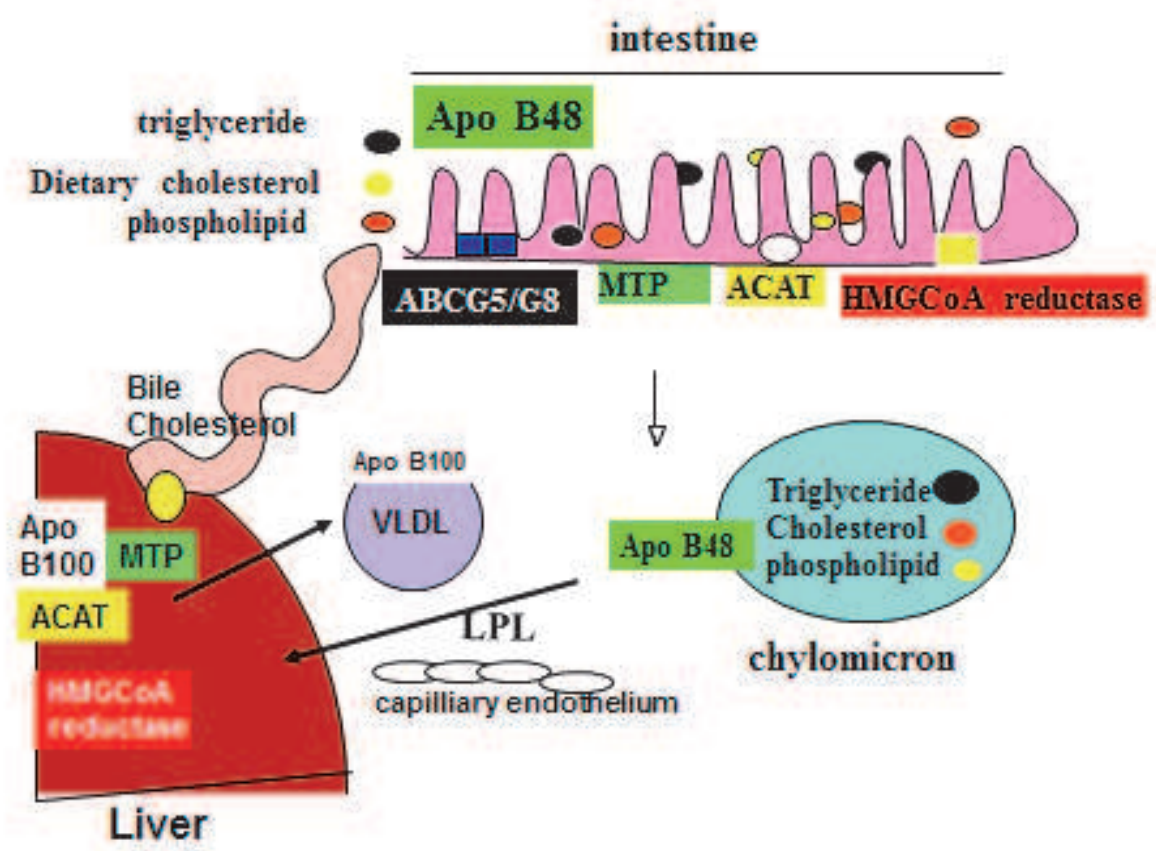

Fig. 3. The chylomicron is formed from dietary cholesterol, triglyceride, and phospholipid together with endogenously synthesised cholesterol for which HMGCoA reductase is the rate-limiting enzyme, and Some of the cholesterol is esterified by the enzyme ACAT. Intestinal cholesterol absorption is facilitated by NPC1L1 and opposed by ABCG5/G8. Intestinally produced apo B48 is the structural protein for the chylomicron and the particle is assembled under the influence of MTP. Most of the chylomicron triglyceride is hydrolised by lipoprotein lipase in the capiliaries prior to uptake of the particle by the liver where it is broken down and reassembled together with apo B100, again under the influence of MTP, and released as VLDL into the circulation.

taken up more quickly and cause greater cholesterol accumulation than those enriched with polyunsaturated fatty acids or monounsaturated fatty acids [95]. They further showed that the inflammatory process and the activity of nuclear factor-kB (NF-kB can be diminished if the Chylomicron remnants are enriched with polyunsaturated fatty acids [96]. This group had previously shown that oxidation of chylomicron remnants delayed uptake by the macrophage CD36 receptor in contrast to LDL where oxidation increases uptake in macrophages. The authors however do make the point that the CD36 receptor and phagocytosis play only a minor role in foam cell formation. The main uptake and internalisation being through the LDL receptor related protein (LRP) and the LDL receptor [97]. GLP-1-like agonists are now being widely used in the treatment of diabetes and have a beneficial effect on glycaemia and also lipidaemia [98]. Xiao et al 2011 [99] have recently shown in healthy men that glucagon acutely regulates hepatic but not intestinal lipoprotein 
metabolism both by decreasing lipoprotein particle production and inhibiting particle clearance. The classic diabetes fasting lipid indices of elevated LDL cholesterol, high triglyceride and low HDL in those with type 1 diabetes is often missing even if they have atherosclerosis[100]. However when adolescents with diabetes are compared to their nondiabetic siblings they have been shown to have higher triglycerides. LDL and lower HDL [101]. The SEARCH for diabetes in youth study (SEARCH) showed similar findings [102]. Guy [103] in a cross sectional study of 512 youths with type 1 diabetes mean duration 4.2 years and 188 healthy control subjects they found that those with HbA1c in the optimal range $(<7.5 \%)$ were similar to controls whereas the poorly controlled subjects had raised total cholesterol, LDL cholesterol and non-HDL cholesterol together with significantly elevated apo B and more small dense LDL particles. The authors conclude that poor glycaemic control is an important mediator of abnormal lipoproteins. Very recently Mangat et al [104] examined the chylomicron in subjects with type 1 diabetes thus extending our knowledge of postprandial lipoprotein metabolism in diabetes. Just like in type 2 diabetes [105-107], Mangat et al show significantly higher concentrations both of fasting apo B48 and a total plasma apo B48 following a sequential meal challenge, than control subjects demonstrating impaired metabolism of chylomicron remnants. Interestingly they also demonstrated arterial retention of remnants ex vivo in type 1 diabetic rats and showed that remnants bound with significant affinity to human biglycan in vivo. They also showed a further 2.3 fold increased binding capacity when they used glycated biglycan.

\section{Chylomicron turnover in diabetes}

The chylomicron is mostly cleared by the liver through the B/E and LDL related protein (LRP) receptors. There is prolonged clearance in diabetes as shown by the length of time apo B48 remains in the circulation following a meal [105-107]. This is related both to compositional abnormalities in the chylomicron and to delay in lipolysis. As stated earlier apo E appears to be deficient on the particle [59]. Perhaps more importantly delipidation of the particle is abnormal. Lipoprotein lipase is an insulin dependent enzyme and in clinical practice treatment that normalises blood sugar is always associated with a reduction in triglyceride. The importance of the postprandial period in triglyceride metabolism and particularly in chylomicron metabolism is often overlooked with reliance on fasting blood sugar as being an indication of good diabetic control. The evidence that the postprandial blood sugar is a better indicator of cardiovascular risk than fasting blood sugar and the close relationship between hyperglycaemia and hypertriglyceridaemia suggests that normalisation of both blood sugar and triglycerides would reduce the atherosclerotic burden Cereillo [108]. Interest is growing in measurement and treatment of the postprandial phase but it is very demanding on both patient and physician. The increase in chylomicronaemia postprandially has a major impact on VLDL composition since the large triglyceride-rich lipoproteins generate small dense LDL [109 110]. Small dense LDL has been shown to be more easily oxidised and therefore has a greater capacity to be taken up by the macrophage. Small dense LDL is more common in diabetes. Many years ago the Scottish group were unable to show much in the way of a relationship between small dense LDL and atherosclerosis in diabetes [111] but more recently in a small study it has been reported LDL size was the stongest marker for clinically apparent as well as non apparent atherosclerosis In Type 2 diabetes [112]. Inhibition of cholesterol absorption with Ezetimibe improves the 
quality of VLDL, IDL and LDL by significantly reducing the triglyceride/cholesterol ratio in these lipoproteins [113] demonstrating the relationship between the chylomicron and the other apo B containing lipoproteins.

\section{High density lipoprotein}

The intimate inverse relationship between triglyceride-rich lipoproteins and HDL is well known and is particularly common in diabetes. The reason why this inverse correlation is so strong is due to the importance of apo A1 and apo E in the formation of HDL. Catabolism of the triglyceride-rich lipoproteins is necessary for the release of apo A1 and apo E, both intestinally and hepatically derived. The delayed catabolism of the triglyceride-rich lipoproteins in diabetes leads to a deficiency of apo A1 and apo E necessary for the formation of the nacent HDL particle with its specific detergent-like properties that can solublise vesicular phospholipid to create discoidal HDL particles [114]. Lipoprotein metabolism starting with the large chylomicron and ending with the small HDL particles is a closely interwoven dynamic milieu designed in times when food was in short supply. It is not surprising that disturbance of this intricate pathway occurs with over feeding or in diabetes when a lack of insulin relative or absolute disturbs energy metabolism.

\section{Conclusion}

The chylomicron is a major cholesterol carrying particle due to the large amount of chylomicrons produced postprandially. Chylomicron cholesterol is delivered to the atherosclerotic plaque and induces foam cell formation. Chylomicron clearance is delayed in diabetes but synthesis is also increased in diabetes. The other important cause of atherosclerosis in diabetes relates to the lipoprotein cascade, increased chylomicron production and decreased clearance leads to an atherogenic LDL (both small dense LDL and an LDL with an increase in esterified cholesterol) leading to increased oxidisability of the particle. Finally the increase in triglyceride-rich lipoproteins results in low HDL, an important atherosclerosis risk factor. Normalisation of the dyslipidaemia of diabetes and in particular chylomicronaemia should be a major goal in the prevention of the increased atherosclerosis found in diabetes

\section{References}

[1] Prout TE University Group Diabetes Program.. A progress report on the Int J Clin Pharmacol Biopharm. 1975;12:244-51.

[2] Action to Control Cardiovascular Risk in Diabetes Study Group, Gerstein HC, Miller ME, Byington RP, Goff DC Jr, Bigger JT, Buse JB, Cushman WC, Genuth S, Ismail-Beigi F, Grimm RH Jr, Probstfield JL, Simons-Morton DG, Friedewald WT. Effects of intensive glucose lowering in type 2 diabetes. N Engl J Med. 2008;12;358:2545-59.

[3] Davidoff F.Music Lessons: What Musicians Can Teach Doctors (and Other Health Professionals). Ann Intern Med. 2011;154:426-9.

[4] Haffner SM, Lehto S, Rönnemaa T, Pyörälä K, Laakso M. Mortality from coronary heart disease in subjects with type 2 diabetes and in nondiabetic subjects with and without prior myocardial infarction. N Engl J Med. 1998;339:229-34 
[5] Evans JM, Wang J, Morris AD: Comparison of cardiovascular risk between patients with type 2 diabetes and those who had had a myocardial infarction: cross sectional and cohort studies. BMJ 324 : 939 -942,2002

[6] Juutilainen A, Lehto S, Rönnemaa T, Pyörälä K, Laakso M. Type 2 diabetes as a "coronary heart disease equivalent": an 18-year prospective population-based study in Finnish subjects. Diabetes Care. 2005;28:2901-7

[7] Bulugahapitiya U, Siyambalapitiya S, Sithole J, Idris I. Is diabetes a coronary risk equivalent? Systematic review and meta-analysis. Diabet Med. 2009;26:142-8.

[8] Wannamethee SG, Shaper AG, Whincup PH, Lennon L, Sattar N Impact of diabetes on cardiovascular disease risk and all-cause mortality in older men: influence of age at onset, diabetes duration, and established and novel risk factors. Arch Intern Med. 2011 14;171:404-10.

[9] Tominaga M, Equchi H, Manaka H, Igarashi K, Kato T, Sekikawa A: Impaired glucose tolerance is a risk factor for cardiovascular disease, but not impaired fasting glucose: the Funagata Diabetes Study. Diabetes Care 22:920-924,

[10] Meigs JB, Nathan DM, Wilson PW, Cupples LA, Singer DE: Metabolic risk factors worsen continuously across the spectrum of nondiabetic glucose tolerance: the Framingham Offspring Study. Ann Intern Med 1998;128: 524- 533

[11] The DECODE study group. European Diabetes Epidemiology Group. Diabetes Epidemiology: Collaborative analysis of Diagnostic criteria in Europe Glucose tolerance and mortality: comparison of WHO and American Diabetes Association diagnostic criteria.. Lancet 1999;354:617-621

[12] Lowell BB. Shulman GL Mitocondrial dysfunction in type 2 diabetes Science 2005; 307;384-387

[13] Weiss R, Dufour S, Taksali SE, Tamborlane WV, Petersen KF, Bonadonna RC, Boselli L, Barbetta G, Allen K, Rife F, Savoye M, Dziura J, Sherwin R, Shulman GI, Caprio S. Prediabetes in obese youth: a syndrome of impaired glucose tolerance, severe insulin resistance, and altered myocellular and abdominal fat partitioning. Lancet.2003;362;951-7

[14] Robins SJ, Lyass A, Zachariah JP, Massaro JM, Vasan RS. Insulin Resistance and the Relationship of a Dyslipidemia to Coronary Heart Disease: The Framingham Heart Study. Arterioscler Thromb Vasc Biol. 2011 Feb 10. [Epub ahead of print]PMID: 21311041

[15] Khaw KT, Wareham N, Bingham S, Luben R, Welch A, Day N. Association of hemoglobin A1c with cardiovascular disease and mortality in adults: the European Prospective Investigation into Cancer in Norfolk. Ann Intern Med. 2004;141:413-20

[16] Selvin E, Marinopoulos S, Berkenblit G, Rami T, Brancati FL, Powe NR, Golden SH. Meta-analysis: glycosylated hemoglobin and cardiovascular disease in diabetes mellitus. Ann Intern Med. 2004 ; 141:421-31

[17] Chamnan P, Simmons RK, Jackson R, Khaw KT, Wareham NJ, Griffin SJ Non-diabetic hyperglycaemia and cardiovascular risk: moving beyond categorisation to individual interpretation of absolute risk. Diabetologia. 2011 ;54:291-9.

[18] Polak JF, Backlund JY, Cleary PA, Harrington AP, O'Leary DH, Lachin JM, Nathan DM; DCCT/EDIC Research Group.Progression of carotid artery intima-media thickness during 12 years in the Diabetes Control and Complications Trial/Epidemiology of Diabetes Interventions and Complications (DCCT/EDIC) study.Diabetes. 2011;60:607-13 
[19] Rury R. Holman RR, Sanjoy KP,. Bethel AB, Matthews DR, Neil HAW, 10-Year Followup of Intensive Glucose Control in Type 2 Diabetes N Engl J Med 2008; 359:15771589

[20] UK Prospective Diabetes Study (UKPDS) Group Intensive blood-glucose control with sulphonylureas or insulin compared with conventional treatment and risk of complications in patients with type 2 diabetes (UKPDS 33). Lancet. 1998;352;837853.

[21] Camafort M, Alvarez-Rodríguez LR, Muñoz-Torrero JF, Sahuquillo JC, López-Jiménez L, Coll R, Monreal M; FRENA Investigators Glucose control and outcome in patients with stable diabetes and previous coronary, cerebrovascular or peripheral artery disease. Findings from the FRENA Registry.Diabet Med. 2011;28:73-80..

[22] van den Berghe G, Wouters P, Weekers F, Verwaest C, Bruyninckx F, Schetz M, Vlasselaers D, Ferdinande P, Lauwers P, Bouillon R. Intensive insulin therapy in the critically ill patients. N Engl J Med. 2001;345:1359-67.

[23] Kavanagh BP, McCowen KC Glycemic control in the ICU. N Engl J Med. 2010 ;363:2540-6. Review.

[24] Shafrir E, Gutman A. Patterns of decrease of free fatty acids during glucoose tolerence tests Diabetes.1965;14:77-83.

[25] Shafrir E, Raz I. Diabetes: mellitus or lipidus? Diabetologia. 2003;46:433-40.

[26] Haemmerle G, Lass A, Zimmermann R, Gorkiewicz G, Meyer C, Rozman J, Heldmaier G, Maier R, Theussl C, Eder S, Kratky D, Wagner EF, Klingenspor M, Hoefler G, Zechner R. Defective lipolysis and altered energy metabolism in mice lacking adipose triglyceride lipase. Science. 2006;312;734-7

[27] Osuga J, Ishibashi S, Oka T, Yagyu H, Tozawa R, Fujimoto A, Shionoiri F, Yahagi N, Kraemer FB, Tsutsumi O, Yamada N Targeted disruption of hormone-sensitive lipase results in male sterility and adipocyte hypertrophy, but not in obesity. Proc Natl Acad Sci USA. 2000;97:787-92

[28] Karlsson M, Contreras JA, Hellman U, Tornqvist H, Holm C. cDNA cloning, tissue distribution, and identification of the catalytic triad of monoglyceride lipase. Evolutionary relationship to esterases, lysophospholipases, and haloperoxidases. J Biol Chem. 1997 ;272: 27218-23

[29] Zimmermann R, Strauss JG, Haemmerle G, Schoiswohl G, Birner-Gruenberger R, Riederer M, Lass A, Neuberger G, Eisenhaber F, Hermetter A, Zechner R. Fat mobilization in adipose tissue is promoted by adipose triglyceride lipase. Science. 2004;306;1383-6.

[30] Schoiswohl G, Schweiger M, Schreiber R, Gorkiewicz G, Preiss-Landl K, Taschler U, Zierler KA, Radner FP, Eichmann TO, Kienesberger PC, Eder S, Lass A, Haemmerle G, Alsted TJ, Kiens B, Hoefler G, Zechner R, Zimmermann R. Adipose triglyceride lipase plays a key role in the supply of the working muscle with fatty acids. J Lipid Res. 2010;51:490-9.

[31. Haemmerle G, Zimmermann R, Hayn M, Theussl C, Waeg G, Wagner E, Sattler W, Magin TM, Wagner EF, Zechner R.Hormone-sensitive lipase deficiency in mice causes diglyceride accumulation in adipose tissue, muscle, and testis. J Biol Chem. 2002;277: 4806-15.

[32] Lass A, Zimmermann R, Oberer M, Zechner R. Lipolysis - a highly regulated multienzyme complex mediates the catabolism of cellular fat stores. Prog Lipid Res. 2011 50:14-27. Review 
[33] Yang Q, Graham TE, Mody N, Preitner F, Peroni OD, Zabolotny JM, Kotani K, Quadro $\mathrm{L}$, Kahn BB. Serum retinol binding protein 4 contributes to insulin resistance in obesity and type 2 diabetes. Nature. 2005;436:356-62

[34] Cholesterol Treatment Trialists' (CTT) Collaboration, Baigent C, Blackwell L, Emberson J, Holland LE, Reith C, Bhala N, Peto R, Barnes EH, Keech A, Simes J, Collins R. Efficacy and safety of more intensive lowering of LDL cholesterol: a meta-analysis of data from 170,000 participants in 26 randomised trials. Lancet 2010 376;1670-81

[35] Abifadel M, Varret M, Rabès JP, Allard D, Ouguerram K, Devillers M, Cruaud C, Benjannet S, Wickham L, Erlich D, Derré A, Villéger L, Farnier M, Beucler I, Bruckert E, Chambaz J, Chanu B, Lecerf JM, Luc G, Moulin P, Weissenbach J, Prat A, Krempf M, Junien C, Seidah NG, Boileau C.Mutations in PCSK9 cause autosomal dominant hypercholesterolemia. Nat Genet. 2003;34:154-6

[36] Horton JD, Cohen JC, Hobbs HH. PCSK9: a convertase that coordinates LDL catabolism. J Lipid Res. 2009;50 Suppl:S172-7..

[37] Steinberg and Witztum Inhibition of PCSK9. A powerful weapon for achieving ideal cholesterol levels. PNAS 2009 106; 9546-9547

[38] Davignon J, Dubuc G. Statins and ezetimibe modulate plasma proprotein convertase subtilisin kexin-9 (PCSK9) levels. Trans Am Clin Climatol Assoc. 2009;120:163-73.

[39] Konrad RJ, Troutt JS, Cao G. Effects of currently prescribed LDL-C-lowering drugs on PCSK9 and implications for the next generation of LDL-C-lowering agents. Lipids Health Dis. 2011;10:38

[40] Chan JC, Piper DE, Cao Q, Liu D, King C, Wang W, Tang J, Liu Q, Higbee J, Xia Z, Di Y, Shetterly S, Arimura Z, Salomonis H, Romanow WG, Thibault ST, Zhang R, Cao P, Yang XP, Yu T, Lu M, Retter MW, Kwon G, Henne K, Pan O, Tsai MM, Fuchslocher B, Yang E, Zhou L, Lee KJ, Daris M, Sheng J, Wang Y, Shen WD, Yeh WC, Emery M, Walker NP, Shan B, Schwarz M, Jackson SM. A proprotein convertase subtilisin/kexin type 9neutralizing antibody reduces serum cholesterol in mice and nonhuman primates. Proc Natl Acad Sci U S A. 2009;106:9820-5.

[41] Shafrir E. Animal models of non-insulin-dependent diabetes. Diabetes Metab Rev. 1992;8:179-208. Review.

[42] Levy E, Lalonde G, Delvin E, Elchebly M, Précourt LP, Seidah NG, Spahis S, RabasaLhoret R, Ziv E.Intestinal and hepatic cholesterol carriers in diabetic Psammomys obesus.Endocrinology. 2010;151:958-70.

[43] Brouwers MC, Troutt JS, van Greevenbroek MM, Ferreira I, Feskens EJ, van der Kallen CJ, Schaper NC, Schalkwijk CG, Konrad RJ, Stehouwer CD. Plasma proprotein convertase subtilisin kexin type 9 is not altered in subjects with impaired glucose metabolism and type 2 diabetes mellitus, but its relationship with non-HDL cholesterol and apolipoprotein B may be modified by type 2 diabetes mellitus: The CODAM study. Atherosclerosis. 2011 Mar 25. [Epub ahead of print]

[44] Pyörälä K, Ballantyne CM, Gumbiner B, Lee MW, Shah A, Davies MJ, Mitchel YB, Pedersen TR, Kjekshus J; Scandinavian Simvastatin Survival Study (4S). Reduction of cardiovascular events by simvastatin in nondiabetic coronary heart disease patients with and without the metabolic syndrome: subgroup analyses of the Scandinavian Simvastatin Survival Study (4S). Diabetes Care. 2004;27:1735-40.

[45] Heart Protection Study Collaborative Group. MRC/BHF Heart Protection Study of cholesterol lowering with simvastatin in 20536 high-risk individuals: a randomised placebo-controlled trial. Lancet 2002;360:7-22. 
[46] Heart Protection Study Collaborative Group. Randomized trial of the effects of cholesterol-lowering with simvastatin on peripheral vascular and other major vascular outcomes in 20,536 people with peripheral arterial disease and other highrisk conditions. J Vasc Surg. 2007;45:645-654;

[47] Kontush A, Chapman MJ. Antiatherogenic function of HDL particle subpopulations: focus on antioxidative activities. Curr Opin Lipidol. 2010;21:312-8. Review

[48] Nordestgaard BG, Benn M, Schnohr P, Tybjaerg-Hansen A Nonfasting triglycerides and risk of myocardial infarction, ischemic heart disease, and death in men and women. JAMA. 2007;298:299-308

[49] Bansal S, Buring JE, Rifai N, Mora S, Sacks FM, Ridker PM Fasting compared with nonfasting triglycerides and risk of cardiovascular events in women. JAMA.2007;298:309-16.

[50] Sluijs I, van der Schouw YT, van der A DL, Spijkerman AM, Hu FB, Grobbee DE, Beulens JW. Carbohydrate quantity and quality and risk of type 2 diabetes in the European Prospective Investigation into Cancer and Nutrition-Netherlands (EPICNL) Study. Am J Clin Nutr. 2010;92:905-11.

[51] Haubrock J, Nöthlings U, Volatier JL, Dekkers A, Ocké M, Harttig U, Illner AK, Knüppel S, Andersen LF, Boeing H; on behalf of the European Food Consumption Validation Consortium. Estimating Usual Food Intake Distributions by Using the Multiple Source Method in the EPIC-Potsdam Calibration Study. J Nutr. 2011 Mar 23.

[52] van Dieren S, Peelen LM, Nöthlings U, van der Schouw YT, Rutten GE, Spijkerman AM, van der A DL, Sluik D, Boeing H, Moons KG, Beulens JW. External validation of the UK Prospective Diabetes Study (UKPDS) risk engine in patients with type 2 diabetes. Diabetologia. 2011;54:264-70.

[53] No authors listed]Effect of fenofibrate on progression of coronary-artery disease in type 2 diabetes: the Diabetes Atherosclerosis Intervention Study, a randomised study. Lancet. 2001;357;905-10.

[54] Keech A, Simes RJ, Barter P, Best J, Scott R, Taskinen MR, Forder P, Pillai A, Davis T, Glasziou P, Drury P, Kesäniemi YA, Sullivan D, Hunt D, Colman P, d'Emden M, Whiting M, Ehnholm C, Laakso M; FIELD study investigatorsEffects of long-term fenofibrate therapy on cardiovascular events in 9795 people with type 2 diabetes mellitus (the FIELD study): randomised controlled trial. Lancet. 2005;366;1849-61.

[55] Jun M, Foote C, Lv J, Neal B, Patel A, Nicholls SJ, Grobbee DE, Cass A, Chalmers J, Perkovic V. Effects of fibrates on cardiovascular outcomes: a systematic review and meta- analysis. Lancet. 2010;375;1875-84

[56] Scott R, O'Brien R, Fulcher G, Pardy C, D'Emden M, Tse D, Taskinen MR, Ehnholm C, Keech A; Fenofibrate Intervention and Event Lowering in Diabetes (FIELD) Study Investigators. Effects of fenofibrate treatment on cardiovascular disease risk in 9,795 individuals with type 2 diabetes and various components of the metabolic syndrome: the Fenofibrate Intervention and Event Lowering in Diabetes (FIELD) study. Diabetes Care. 2009;32:493-8.

[57] Rizzo M, Rini GB, Berneis K The clinical relevance of LDL size and subclasses modulation in patients with type-2 diabetes. Exp Clin Endocrinol Diabetes. 2007 115:477-82. Review.

[58] Adiels M, Olofsson SO, Taskinen MR, Borén J. Diabetic dyslipidaemia. Curr Opin Lipidol. 2006;17:238-46. Review. 
[59] Phillips C, Madigan C, Owens D, Collins P, Tomkin GH. Defective chylomicron synthesis as a cause of delayed particle clearance in diabetes? Int J Exp Diabetes Res. 2002;3:171-8

[60] Matthan NR, Pencina M, LaRocque JM, Jacques PF, D'Agostino RB, Schaefer EJ, Lichtenstein AH. Alterations in cholesterol absorption/synthesis markers characterize Framingham offspring study participants with CHD. J Lipid Res. 2009 Sep;50(9):1927-35. Epub 2009 May 12.PMID: 19436064 [PubMed - in process]

[61] Matthan NR, Resteghini N, Robertson M, Ford I, Shepherd J, Packard C, Buckley BM, Jukema JW, Lichtenstein AH, Schaefer EJ; PROSPER Group. Cholesterol absorption and synthesis markers in individuals with and without a CHD event during pravastatin therapy: insights from the PROSPER trial. J Lipid Res. 2010 ;51:202-9.

[62] Silbernagel G, Fauler G, Renner W, Landl EM, Hoffmann MM, Winkelmann BR, Boehm BO, März W. The relationships of cholesterol metabolism and plasma plant sterols with the severity of coronary artery disease. J Lipid Res. 2009;50:334-41.

[63] Lakoski SG, Xu F, Vega GL, Grundy SM, Chandalia M, Lam C, Lowe RS, Stepanavage ME, Musliner TA, Cohen JC, Hobbs HH. Indices of cholesterol metabolism and relative responsiveness to ezetimibe and simvastatin. J Clin Endocrinol Metab. 2010;95:800-9.

[64] Miettinen TA, Gylling H Blood glucose and the metabolism of cholesterol in coronary patients with and without simvastatin treatment. Subgroup analysis of Scandinavian Simvastatin Survival Study (4S).Clin Chim Acta. 2007 Apr;379(12):53-8.

[65] Kern F Jr. Normal plasma cholesterol in an 88-year-old man who eats 25 eggs a day. Mechanisms of adaptation. N Engl J Med. 1991;324:896-9.

[66] Altmann SW, Davis HR Jr, Zhu IJ, Yao X, Hoos LM, Tetzloff F, Iyer Sp, Maguire M, Golovko A, Zeng M, Wang L, Murgolo N, Graziano MP: Niemann-Pick C1 Like 1 protein is critical for intestinal cholesterol absorption. Science 2004;303:1201-4,

[67] Deficiency of Niemann-Pick C1 Like 1 prevents atherosclerosis in ApoE-/- mice. Davis HR Jr, Hoos LM, Tetzloff G, Maguire M, Zhu LJ, Graziano MP, Altmann SW. Arterioscler Thromb Vasc Biol. 2007;27:841-9.

[68] Davis HR Jr, Lowe RS, Neff DR. Effects of ezetimibe on atherosclerosis in preclinical models. Atherosclerosis. 2011;215:266-78.

[69] Tremblay AJ, Lamarche B, Lemelin V, Hoos L, Benjannet S, Seidah NG, Davis HR Jr, Couture P. Atorvastatin increases intestinal expression of NPC1L1 in hyperlipidemic men. J Lipid Res. 2011;52:558-65.

[70] Gleeson A, Owens D, Collins P, Johnson, Tomkin GH. The relationship between cholesterol absorption and intestinal cholesterol synthesis in the diabetic rat model. Internat J Exp Diab Res 2000;1;203-210

[71] Lally S, Tan CY, Owens D, Tomkin GH. Messenger RNA levels of genes involved in dysregulation of postprandial lipoproteins in type 2 diabetes: the role of NiemannPick C1-like 1, ATP-binding cassette, transporters G5 and G8, and of microsomal triglyceride transfer protein. Diabetologia. 2006;49:1008-16.

[72] Lally S, Owens D, Tomkin GH. Genes that affect cholesterol synthesis, cholesterol absorption and chylomicron assembly. The relationship between the liver and intestine in control and streptozotosin diabetic rats Metabolism 2007:56:430-438 
[73] Intestinal and hepatic cholesterol carriers in diabetic Psammomys obesus. Levy E, Lalonde G, Delvin E, Elchebly M, Précourt LP, Seidah NG, Spahis S, Rabasa-Lhoret R, Ziv E. Endocrinology. 2010;151:958-70.

[74] Levy E, Spahis S, Ziv E, Marette A, Elchebly M, Lambert M, Delvin E. Overproduction of intestinal lipoprotein containing apolipoprotein B-48 in Psammomys obesus: impact of dietary n-3 fatty acids. Diabetologia. 2006;49:1937-45.

[75] Berge KE, Tian H, Graf GA et al. Accumulation of dietary cholesterol in sitosterolemia caused by mutations in adjacent ABC transporters. Science 2000;290:1771-5,

[76] Graf GA, Yu L, Li WP, Gerard R, Tuma PL, Cohen JC, Hobbs HH. ABCG5 and ABCG8 are obligate heterodimers for protein trafficking and biliary excretion. J Biol Chem $2003 ; 278 ; 48275-48282$

[77] Kosters A, Kunne C, Looije N, Patel SB, Oude Elferink RP, Groen AK. The mechanism of ABCG5/ABCG8 in biliary cholesterol secretion in mice. J Lipid Res. 2006 47:1959-66.

[78] Wang HH, Patel SB, Carey MC, Wang DQ. Quantifying anomalous intestinal sterol uptake, lymphatic transport, and biliary secretion in Abcg8(-/-) mice. Hepatology. 2007;45:998-1006

[79] Santosa S, Demonty I, Lichtenstein AH, Ordovas JM, Jones PJ. Single nucleotide polymorphisms in ABCG5 and ABCG8 are associated with changes in cholesterol metabolism during weight loss. J Lipid Res. 2007;48:2607-13.

[80] Gylling H, Hallikainen M, Pihlajamäki J, Agren J, Laakso M, Rajaratnam RA, Rauramaa R, Miettinen TA. Polymorphisms in the ABCG5 and ABCG8 genes associate with cholesterol absorption and insulin sensitivity. J Lipid Res. 2004;45:1660-5

[81] Blocks VW, Bakker-Van Waarde WM, Verkade HJ, Kema IP, Wolters H, Vink E, Groen AK, Kuipers F. Down-regulation of hepatic and intestinal Abcg5 and Abcg8 expression associated with altered sterol fluxes in rats with streptozotocin-induced diabetes. Diabetologia. 2004;47:104-12.

[82] Lally S, Owens D, Tomkin GH The different effect of pioglitazone as compared to insulin on expression of hepatic and intestinal genes regulating post-prandial lipoproteins in diabetes Atherosclerosis. 2007;193:343-51.

[83] Lally S, Owens D, Tomkin GH. Genes that affect cholesterol synthesis, cholesterol absorption and chylomicron assembly. The relationship between the liver and intestine in control and streptozotosin diabetic rats Metabolism 2007:56:430-438

[84] Aggarwal D, West KL, Zern TL, Shrestha S, Vergara-Jimenez M, Fernandez ML. JTT130, a microsomal triglyceride transfer protein (MTP) inhibitor lowers plasma triglycerides and LDL cholesterol concentrations without increasing hepatic triglycerides in guinea pigs. BMC Cardiovasc Disord. 2005 ;27;5:30.

[85] Kim E, Campbell S, Schueller O, Wong E, Cole B, Kuo J, Ferkany J, Ellis J, Sweetnam P. A Small Molecule Inhibitor of Enterocytic Microsomal Triglyceride Transfer Protein; SLx-4090, Biochemical, Pharmacodynamic, Pharmacokinetic and Safety Profile. J Pharmacol Exp Ther. 2011 Mar 15. [Epub ahead of print] PMID:2140654

[86] Phillips C, Mullan K, Owens D, Tomkin GH. A common microsomal triglyceride transfer protein polymorphism significantly reduces low density lipoprotein cholesterol in type 2 diabetic patients through its effect on the triglyceride-rich lipoproteins. QJM 2004;97;211-218

[87] Karpe F, Lundahl B, Ehrenborg E, Eriksson P, Hamsten A. A common functional polymorphism in the promoter region of the microsomal triglyceride transfer 
protein gene influences plasma LDL levels. Atheroscler Thromb Vasc Biol $1998 ; 18 ; 756-761$

[88] Phillips C, Anderton K, Bennett A et al. Intestinal rather than hepatic microsomal triglyceride transfer protein as a cause of postprandial dyslipidaemia in diabetes. Metabolism 2002;51:847-852.

[89] Gleeson A, Anderton K, Owens D, et al The role of microsomal triglyceride transfer protein and dietary cholesterol in chylomicron production in diabetes. Diabetologia 1999;42:944-949

[90] Lally S, Owens D, Tomkin GH. The different effect of pioglitazone as compared to insulin on expression of hepatic and intestinal genes regulating post-prandial lipoproteins in diabetes. Atherosclerosis 2007;193:343-51.

[91] Qin B, Qiu W, Avramoglu RK, Adeli K. Tumor necrosis factor-alpha induces intestinal insulin resistance and stimulates the overproduction of intestinal apolipoprotein B48-containing lipoproteins. Diabetes 2007;56:450-61.

[92] Zoltowska M, Ziv E, Delvin E, Sinnett D, Kalman R, Garofalo C, Seidman E, Levy E.Cellular aspects of intestinal lipoprotein assembly in Psammomys obesus: a model of insulin resistance and type 2 diabetes. Diabetes. 2003 Oct;52(10):2539-45.

[93] Yoshimura N, Kinoshita M, Teramoto T.Isolation and characterization of apolipoprotein B48-containing lipoproteins with a monoclonal antibody against apolipoprotein B48. J Atheroscler Thromb. 2009;16(6):740-7.

[94] Botham KM, Bravo E, Elliott J, Wheeler-Jones CP. Direct interaction of dietary lipids carried in chylomicron remnants with cells of the artery wall: implications for atherosclerosis development. Curr Pharm Des. 2005;11:3681-3695.

[95] Proctor SD, Vine DF, Mamo JC. Arterial retention of apolipoprotein B(48)- and B(100)containing lipoproteins in atherogenesis. Curr Opin Lipidol. 2002;13:461-470.

[96] De Pascale C, Avella M, Perona JS, Ruiz-Gutierrez V, Wheeler-Jones CP, Botham KM. Fatty acid composition of chylomicron remnant-like particles influences their uptake and induction of lipid accumulation in macrophages. FEBS J. 2006;273:56325640.

[97] De Pascale C, Graham V, Fowkes RC, Wheeler-Jones CP, Botham KM.Suppression of nuclear factor-kappaB activity in macrophages by chylomicron remnants: modulation by the fatty acid composition of the particles.FEBS J. 2009 Oct;276(19):5689-702. Epub 2009 Sep 2

[98] Bejta F, Moore EH, Avella M, Gough PJ, Suckling KE, Botham KM Oxidation of chylomicron remnant-like particles inhibits their uptake by THP-1 macrophages by apolipoprotein E-dependent processes. Biochim Biophys Acta. 2007 Jul;1771(7):90110.

[99] Bunck MC, Cornér A, Eliasson B, Heine RJ, Shaginian RM, Wu Y, Yan P, Smith U, YkiJärvinen $H$, Diamant $M$, Taskinen MR. One-year treatment with exenatide vs. insulin glargine: effects on postprandial glycemia, lipid profiles, and oxidative stress. Atherosclerosis. 2010;212:223-9.

[100] Xiao C, Pavlic M, Szeto L, Patterson BW, Lewis GF. Effects of acute hyperglucagonemia on hepatic and intestinal lipoprotein production and clearance in healthy humans. Diabetes. 2011;60:383-90.

[101] Howard BV. Lipoprotein metabolism in diabetes mellitus. J Lipid Res.1987;28:613-28.

[102] Lopes-Virella MF, Wohltmann HJ, Loadholt CB, Buse MG. Plasma lipids and lipoproteins in young insulin-dependent diabetic patients: relationship with control. Diabetologia. 1981;21:216-23. 
[103] James RW, Pometta D: Differences in lipoprotein subfraction composition and distribution between type I diabetic men and control subjects. Diabetes 39:11581164,1990

[104] Guy J, Ogden L, Wadwa RP, Hamman RF, Mayer-Davis EJ, Liese AD, D'Agostino R Jr, Marcovina S, Dabelea D.Lipid and lipoprotein profiles in youth with and without type 1 diabetes: the SEARCH for Diabetes in Youth case-control study. Diabetes Care. 2009;32:416-20.

[105] Mangat R, Su JW, Lambert JE, Clandinin MT, Wang Y, Uwiera RR, Forbes JM, Vine DF, Cooper ME, Mamo JC, Proctor SDIncreased risk of cardiovascular disease in Type 1 diabetes: arterial exposure to remnant lipoproteins leads to enhanced deposition of cholesterol and binding to glycated extracellular matrix proteoglycans. Diabet Med. 2011;28:61-72.

[106] Curtin A, Deegan P, Owens D, Collins P, Johnson A, Tomkin GH. Elevated triglyceride- rich lipoproteins in diabetes. A study of apolipoprotein B-48. Acta Diabetol 1996;33:205-10.

[107] Curtin A, Deegan P, Owens D, Collins P, Johnson A, Tomkin GH. Intestinally derived lipoprotein particles in non-insulin-dependent diabetic patients with and without hypertriglyceridaemia. Acta Diabetol. 1995;32:244-50.

[108] Curtin A, Deegan P, Owens D, Collins P, Johnson A, Tomkin GH. Alterations in apolipoprotein B-48 in the postprandial state in NIDDM. Diabetologia. 1994;37:1259-64.

[109] Ceriello A. Does postprandial blood glucose matter and why? Endocrinol Nutr. 2009;56 Suppl 4:8-11

[110] Watson TD, Caslake MJ, Freeman DJ, Griffin BA, Hinnie J, Packard CJ, Shepherd J: Determinants of LDL subfraction distribution and concentrations in young normolipidemic subjects. Arterioscler Thromb, 1994; 14: 902-910

[111] Gaw A, Packard CJ, Lindsay GM, Griffin BA, Caslake MJ, Lorimer AR, Shepherd J Overproduction of small very low density lipoproteins (Sf 20-60) in moderate hypercholesterolemia: relationships between apolipoprotein B kinetics and plasma lipoproteins. J Lipid Res. 1995;36:158-71.

[112] Colhoun HM, Otvos JD, Rubens MB, Taskinen MR, Underwood SR, Fuller JH.Lipoprotein subclasses and particle sizes and their relationship with coronary artery calcification in men and women with and without type 1 diabetes. Diabetes. $2002 ; 51: 1949-56$

[113] Berneis K, Jeanneret C, Muser J, Felix B, Miserez AR. Low-density lipoprotein size and subclasses are markers of clinically apparent and non-apparent atherosclerosis in type 2 diabetes.Metabolism. $2005 ; 54: 227-34$.

[114] Bozzetto L, Annuzzi G, Corte GD, Patti L, Cipriano P, Mangione A, Riccardi G, Rivellese AA. Ezetimibe beneficially influences fasting and postprandial triglyceride-rich lipoproteins in type 2 diabetes. Atherosclerosis. 2011 Mar 15. Epub ahead of print]

[115] Lund-Katz S, Phillips MC High density lipoprotein structure-function and role in reverse cholesterol transport. Subcell Biochem. 2010;51:183-227. Review. 


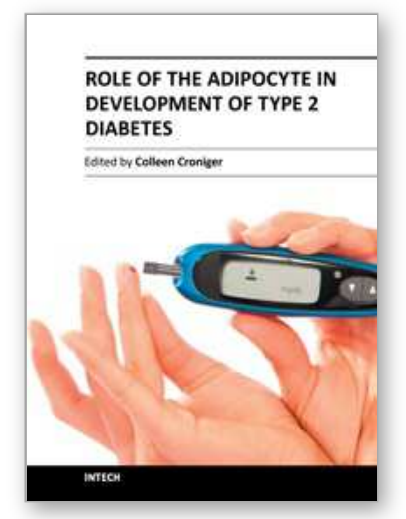

\author{
Role of the Adipocyte in Development of Type 2 Diabetes \\ Edited by Dr. Colleen Croniger
}

ISBN 978-953-307-598-3

Hard cover, 372 pages

Publisher InTech

Published online 22, September, 2011

Published in print edition September, 2011

Adipocytes are important in the body for maintaining proper energy balance by storing excess energy as triglycerides. However, efforts of the last decade have identified several molecules that are secreted from adipocytes, such as leptin, which are involved in signaling between tissues and organs. These adipokines are important in overall regulation of energy metabolism and can regulate body composition as well as glucose homeostasis. Excess lipid storage in tissues other than adipose can result in development of diabetes and nonalcoholic fatty liver disease (NAFLD). In this book we review the role of adipocytes in development of insulin resistance, type 2 diabetes and NAFLD. Because type 2 diabetes has been suggested to be a disease of inflammation we included several chapters on the mechanism of inflammation modulating organ injury. Finally, we conclude with a review on exercise and nutrient regulation for the treatment of type 2 diabetes and its co-morbidities.

\title{
How to reference
}

In order to correctly reference this scholarly work, feel free to copy and paste the following:

Gerald H. Tomkin and Daphne Owens (2011). Disturbed Chylomicron Metabolism in Type 2 Diabetes - A Preventable Cause of Atherosclerosis?, Role of the Adipocyte in Development of Type 2 Diabetes, Dr. Colleen Croniger (Ed.), ISBN: 978-953-307-598-3, InTech, Available from: http://www.intechopen.com/books/role-ofthe-adipocyte-in-development-of-type-2-diabetes/disturbed-chylomicron-metabolism-in-type-2-diabetes-apreventable-cause-of-atherosclerosis-

\section{INTECH}

open science | open minds

\section{InTech Europe}

University Campus STeP Ri

Slavka Krautzeka 83/A

51000 Rijeka, Croatia

Phone: +385 (51) 770447

Fax: +385 (51) 686166

www.intechopen.com

\section{InTech China}

Unit 405, Office Block, Hotel Equatorial Shanghai

No.65, Yan An Road (West), Shanghai, 200040, China

中国上海市延安西路65号上海国际贵都大饭店办公楼405单元

Phone: +86-21-62489820

Fax: +86-21-62489821 
(C) 2011 The Author(s). Licensee IntechOpen. This chapter is distributed under the terms of the Creative Commons Attribution-NonCommercialShareAlike-3.0 License, which permits use, distribution and reproduction for non-commercial purposes, provided the original is properly cited and derivative works building on this content are distributed under the same license. 